Article

\title{
Friction of Human Skin against Different Fabrics for Medical Use
}

\author{
Luís Vilhena * and Amílcar Ramalho \\ CEMUC, Department of Mechanical Engineering, University of Coimbra, Rua Luís Reis Santos, 3030-788 \\ Coimbra, Portugal; amilcar.ramalho@dem.uc.pt \\ * Correspondence: luis.vilhena@uc.pt; Tel.: +351-239-790-700; Fax: +351-239-790-701
}

Academic Editors: Ille C. Gebeshuber and George van Aken

Received: 1 December 2015; Accepted: 19 February 2016; Published: 1 March 2016

\begin{abstract}
Knowledge of the tribology of human skin is essential to improve and optimize surfaces and materials in contact with the skin. Besides that, friction between the human skin and textiles is a critical factor in the formation of skin injuries, which are caused if the loads and shear forces are high enough and/or over long periods of time. This factor is of particular importance in bedridden patients, since they are not moving about or are confined to wheelchairs. Decubitus ulcers are one of the most frequently-reported iatrogenic injuries in developed countries. The risk of developing decubitus ulcers can be predicted by using the "Braden Scale for Predicting Pressure Ulcer Risk" that was developed in 1987 and contains six areas of risk (cognitive-perceptual, immobility, inactivity, moisture, nutrition, friction/shear), although there are limitations to the use of such tools. The coefficient of friction of textiles against skin is mainly influenced by: the nature of the textile, skin moisture content and ambient humidity. This study will investigate how skin friction (different anatomical regions) varies, rubbing against different types of contacting materials (i.e., fabrics for medical use) under different contact conditions and their relationship in the formation and prevention of decubitus ulcers.
\end{abstract}

Keywords: biotribology; skin friction; fabrics; decubitus

\section{Introduction}

Tribology was first defined in a scientific report as "The science and technology of interacting surfaces in relative motion and the practices related thereto" [1] and involves the study of friction, lubrication and wear. In particular, biotribology is usually defined as the tribological phenomena occurring in biological systems. The tribology of human skin is a research topic that has emerged in the last few decades and has continuously attracted scientific studies since human skin is frequently one of the interacting surfaces in relative motion. Everyday life situations, like shaving, skin care and interaction with touch screens with the index finger, illustrates the importance of optimizing the operational conditions for a given frictional response. Human skin is a soft biomaterial with a very complex surface topography and can be considered as a multilayer composite (epidermis, dermis and subcutis; see Figure 1), with the three layers differing in thickness and strength. 


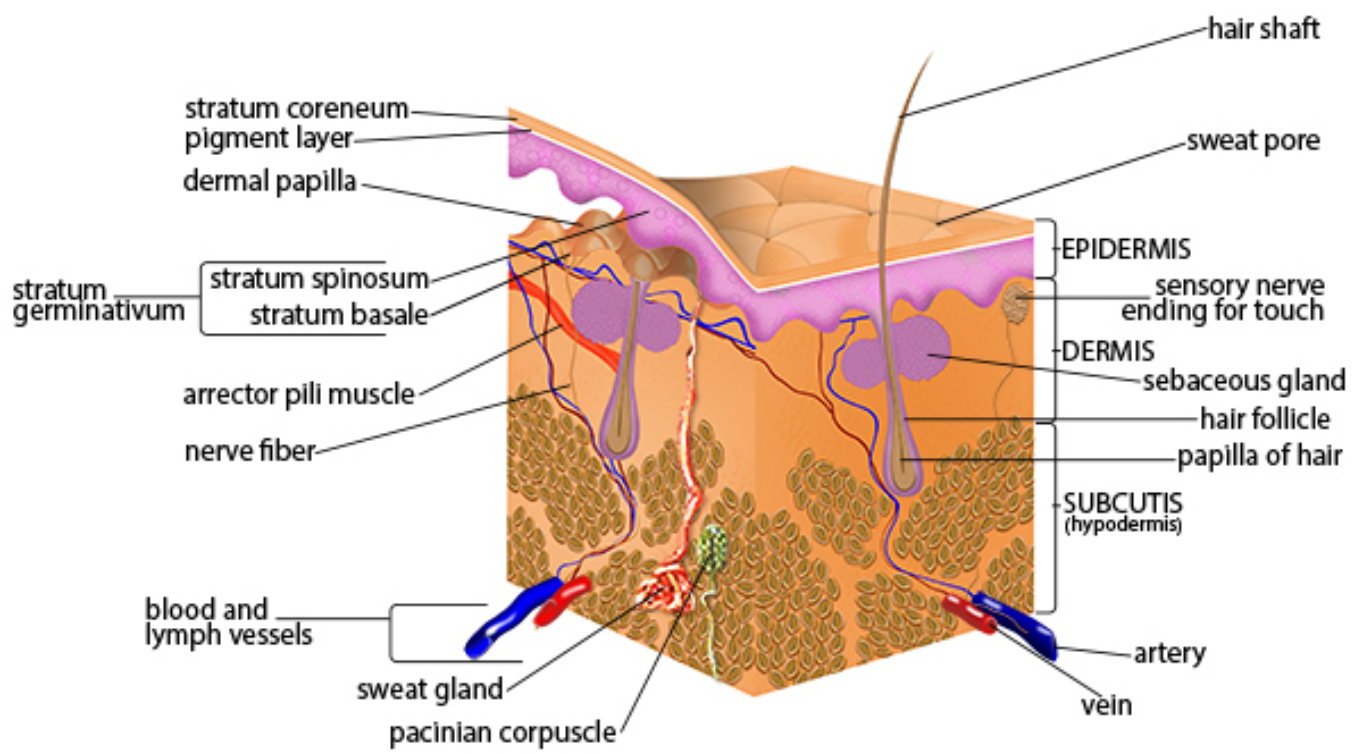

Figure 1. Structure of human skin showing the functional layers (epidermis, dermis and subcutis). By courtesy and with permission of the National Institutes of Health, U.S. Department of Health and Human Services.

According to Johnson et al. [2], human skin is characterized by a nonlinear viscoelastic material behavior. Therefore, Amontons' laws of friction, claiming that the friction force is directly proportional to normal force and independent of the contact area, are not applicable and imply a two-term friction model consisting of an adhesion (sum of the forces required to break the adhesive bonds between the two surfaces at the asperity level), as well as a deformation component (the forces related to the deformation of the bodies in contact) [3]. In order to describe the tribological behavior of human skin, there have been a few theoretical models in the literature to describe the friction mechanism of viscoelastic materials [2,4-6]. According to with Adams et al. [4], adhesion is considered as the main contribution to the friction of human skin, whereas deformation mechanisms play a minor role. Depending on the contact conditions, various effects can come into play.

It was found in recent studies [7-11] that the friction of skin strongly depends on the operating conditions, like moisture, as well as on the presence of water in the interface between skin (in the stratum corneum (SC); see Figure 1) and a contacting surface, with dry skin showing relatively low coefficients of friction, while moist or wet skin is characterized by significantly higher coefficients of friction. Intermediate layers, such as cosmetic applied substances, sweat and sebum excreted from skin into the tribo-interface, also influence the friction behavior of human skin. Other studies investigated gender, age and anatomical sites [12-15]. There are, however, still open research questions: the transition from dry to moist skin conditions has so far not been systematically investigated. Research topics, like tactile perception and haptics in relation to skin tribology, are largely unstudied and poorly understood. This topic is very interesting for the design of surfaces with a pre-defined tactile feel (smooth, soft) that increase the customer's satisfaction, but also for developments and applications in robotics [16]. The analysis of comfort and discomfort in skin product interactions clearly reveals the relative importance of skin friction, since the exploratory procedure that is used to touch a surface, resulting in a somatosensory response/touch perception is a similar to experimentally-determining friction in a reciprocating test [17]. Deformation of the skin and/or high coefficients of friction during skin product interactions could cause discomfort, since the subsurface stress and strains within the skin are influenced by skin friction, and according to Xu et al. [18], a threshold exists for stress at the nociceptor (sensory receptor) located below the skin surface. The earliest experimental investigations suggested soft and smooth materials as pleasant, those that were stiff, rough or coarse 
as unpleasant [19]. The main tribological result of aother study performed by Barnes et al. [20] shows that positive feelings are generated when a finger rubs over a rough surface that is smoother than a fingertip; negative feelings are generated by coarser surfaces. Different experimental techniques have been reported [16], in order to determine the mechanical properties of skin in vivo, based on measurements of torsion, suction, extensibility or ultrasound. In a recent study executed by Ramalho et al. [21], in order to measure in vivo skin friction for different anatomical sites, experiments were carried out using a multiaxial load cell that allows the simultaneous measurement of the normal and tangential forces. The tests consist of sliding the skin surface on a glass disc and simultaneously increasing the normal contact pressure. The results reveal that the friction behavior also depends on the anatomical site. Another study performed by Ramalho et al. [22] in order to assess the coefficient of friction between human skin sliding against different types of fabric shows that wool produces the highest COF in both men and women, while polyamide-based fabric produced the lowest values of COF, as can be seen in Figure 2. In this study performed by Ramalho et al. [22], the friction was measured on the ventral forearm of each volunteer. Nineteen people, both females and males of different ages, were investigated. Error bars correspond to the confidence intervals, assuming a $95 \%$ probability. Concerning the effect of gender, Figure 2 shows similar trends for both females and males.

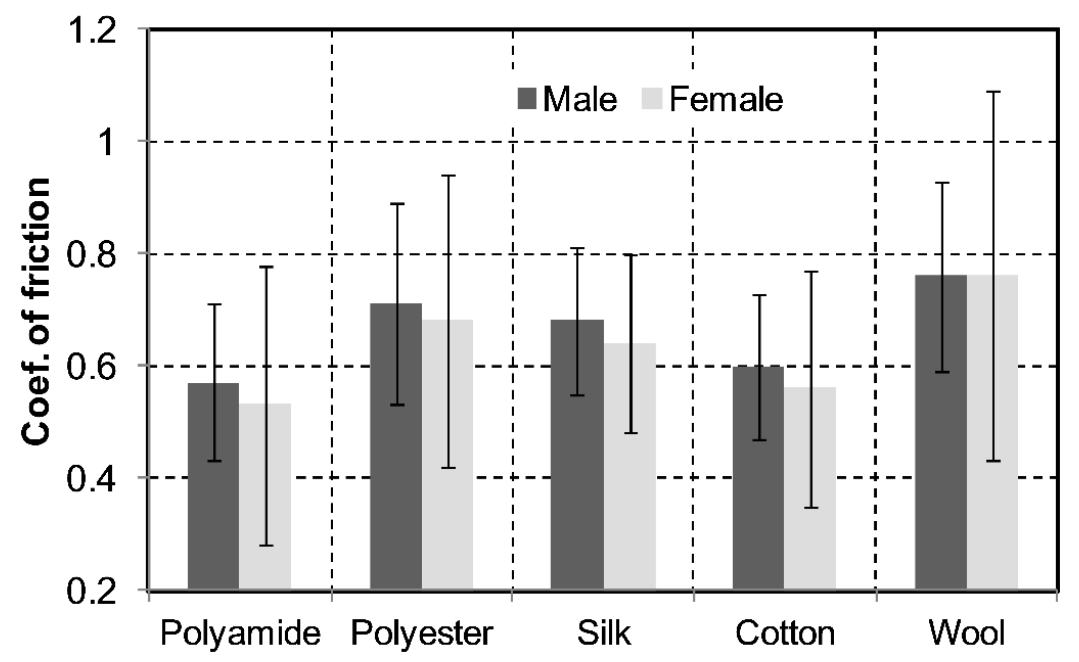

Figure 2. Coefficient of friction (COF) for different fabrics against skin (ventral forearm) [22].

The conclusions of this scientific work will definitely contribute to a better understanding of pressure ulcer prevention. Thus, pressure ulcer prevention requires an interdisciplinary approach, and according to the Agency for Healthcare Research and Quality, the incidence of pressure ulcers is also a healthcare quality indicator. This factor is of utmost importance to hospital quality.

\section{Experimental Section}

\section{Material and Methods}

Four types of hospital fabrics were used during the present investigation (Figure 3). The materials tested include a reference hospital fabric that is used in bed linen, like sheets and pillows (Figure 3a), a foam dressing generally made from a hydrophilic polyurethane foam (Figure 3b), an adult diaper (Figure 3c) and a normal bed protector made of soft non-slip waterproof polyethylene (Figure 3d) that keeps skin away from dampness, reducing the risk of dermatitis and ulceration. The coefficient of friction for the four different fabrics was assessed at one specific body region, the ventral forearm, under natural skin conditions. The volunteer was a 42-year-old Caucasian male. 


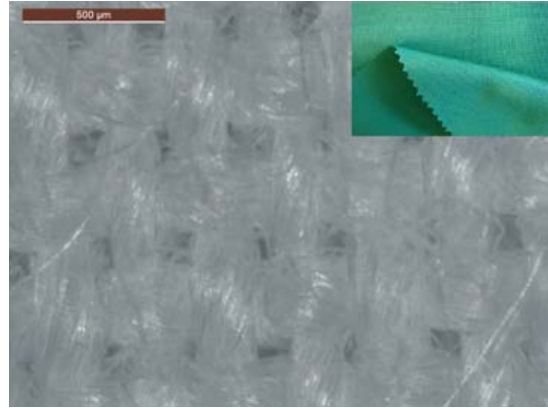

(a)

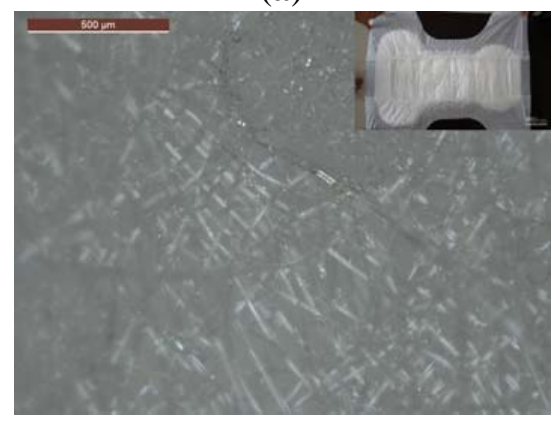

(c)

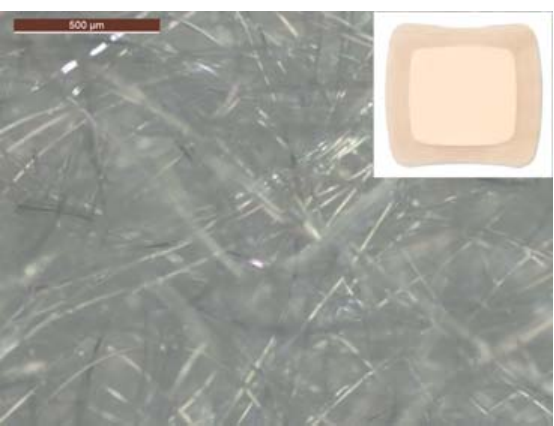

(b)

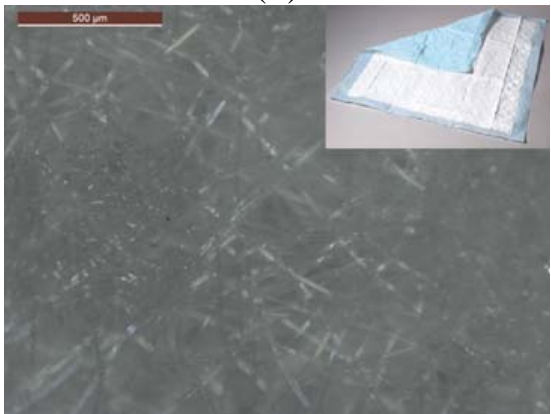

(d)

Figure 3. Optical micrographs of different hospital fabrics used in contact with the skin: (a) reference hospital fabric; (b) foam dressing; (c) adult diaper; and (d) normal bed protector.

Preliminary tests to measure in vivo skin friction were performed using a reference hospital fabric against four different skin regions (palm of the hand, finger pad, ventral forearm and elbow) under different lubricating conditions (natural skin, wet skin and skin after spreading of Vaseline). Prior to the tests, the skin in the natural and undamaged state was rinsed with ethyl alcohol and dried at room temperature (natural skin conditions). To bring the skin to a wet state, a wet napkin was placed on the skin surface for five minutes. Afterwards, the skin was wiped to remove the excess water, and tests were performed. In order to study the effect of a general moisturizing substance, a thick layer of glycerine was spread through over the skin. After a waiting period of five minutes, the skin surface was cleaned with a facial paper tissue, and experimental tests were executed. All experiments were conducted at $22 \pm 2{ }^{\circ} \mathrm{C}$ and $58 \% \pm 10 \%$ relative humidity.

A portable and easily-usable measuring probe, where the test materials are rubbed against skin, was used (see Figure 4). Since a rubber O-ring can be used to fix the textile on the tip (see Figure 4a), different types of hospital fabrics were simply adjusted to the equipment and tested. This probe is based on a multi-component force sensor, whereby the normal and tangential forces can be measured in order to determine the coefficient of friction (see Figure $4 b$ ).

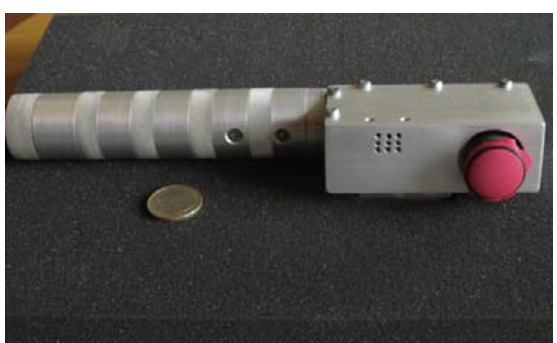

(a)

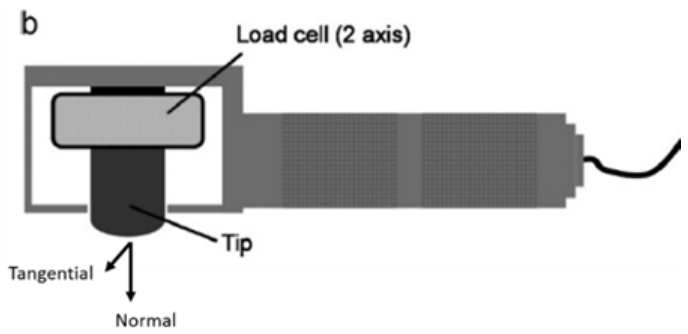

(b)

Figure 4. Skin friction portable measuring probe: (a) picture showing the O-ring and textile; and (b) schematic picture of the multi-component force sensor [22]. 
Friction tests consist of sliding the portable measuring probe on the specific body region and simultaneously increasing the normal load. Typically, the sliding distance and normal load range respectively between 0 and $40 \mathrm{~mm}$ and 0 and $5 \mathrm{~N}$. The tangential force is then computed as a function of the normal applied load. By using the Amontons-Coulomb friction model, it is possible, by fitting an equation to the data points (tangential force against normal force) and calculating the slope of each equation, to determine the coefficient of friction (COF), for each test condition.

\section{Results and Discussion}

Figure 5 shows the evolution of both normal and friction force during the loading phase of a typical friction test. As can be seen in Figure 5, the normal force was varied between approximately 0 and $3.3 \mathrm{~N}$, resulting in a friction force varying between approximately 0 and 1 N. Figure 6 shows the plot of the friction force against normal force. It can be seen that by fitting an equation to the data points, a good correlation with the Amontons-Coulomb linear model was obtained, with the friction force being proportional to the normal applied force. For each different contact condition, three different tests were performed, as shown in Figure 7, and the average coefficient of friction was determined as the slope of the fitted linear line to all data points (tests 1, 2 and 3).

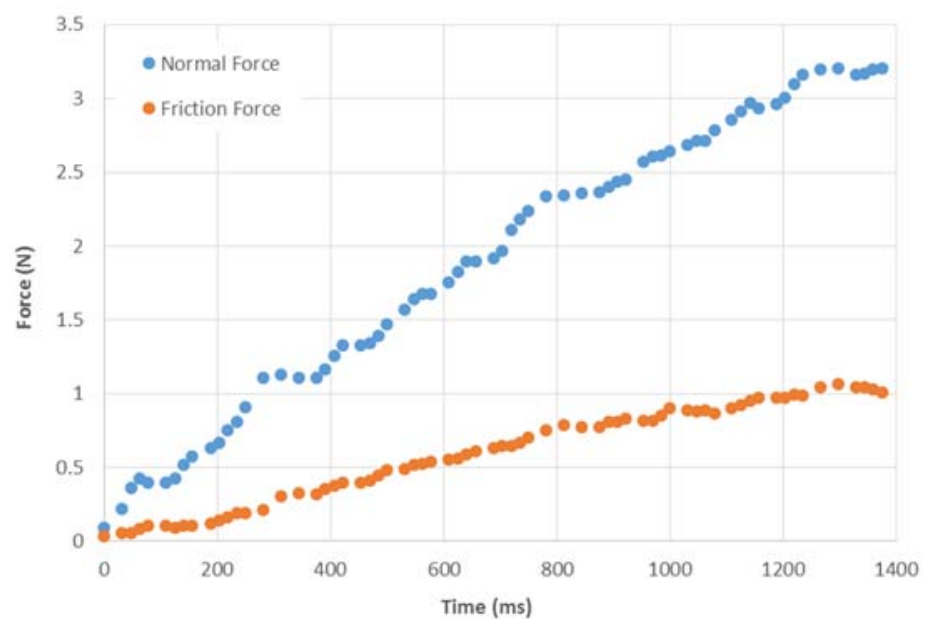

Figure 5. Evolution of both, normal and friction force during the loading phase (hospital fabric: bed protector; body region: ventral forearm).

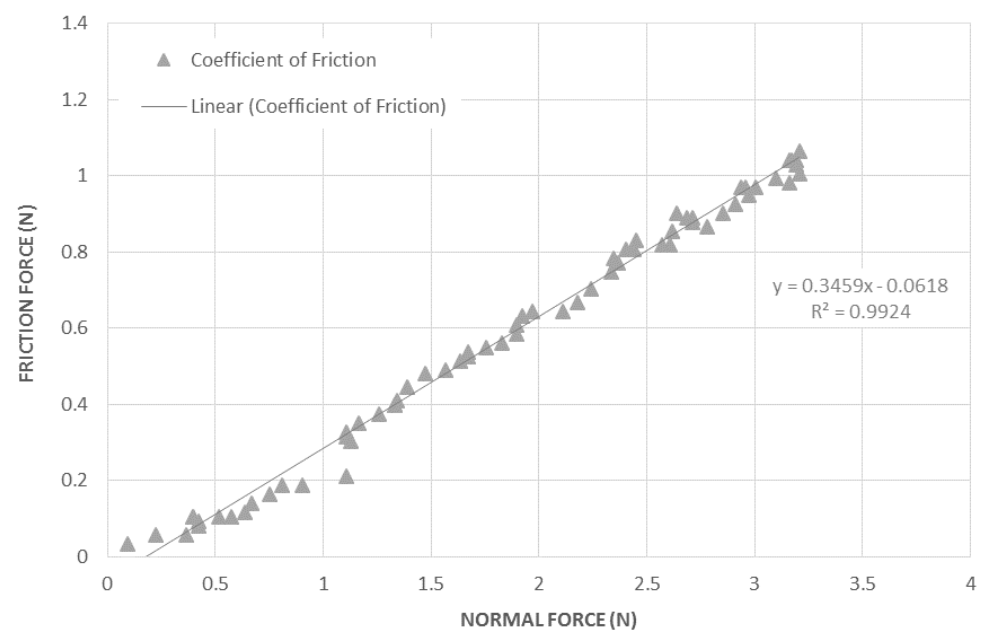

Figure 6. Evolution of friction force against normal force (hospital fabric: bed protector; body region: ventral forearm). 


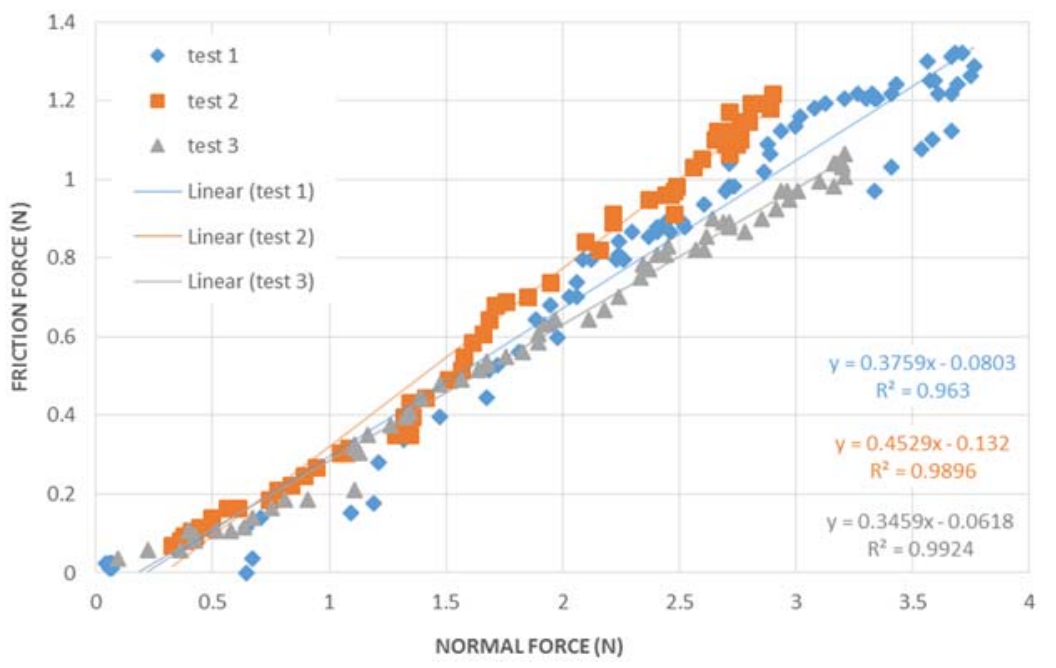

Figure 7. Evolution of friction force against normal force for three different tests with the same contact conditions (hospital fabric: bed protector; body region: ventral forearm).

The average values of the coefficient of friction for the different test conditions can be seen in Figures 8 and 9.

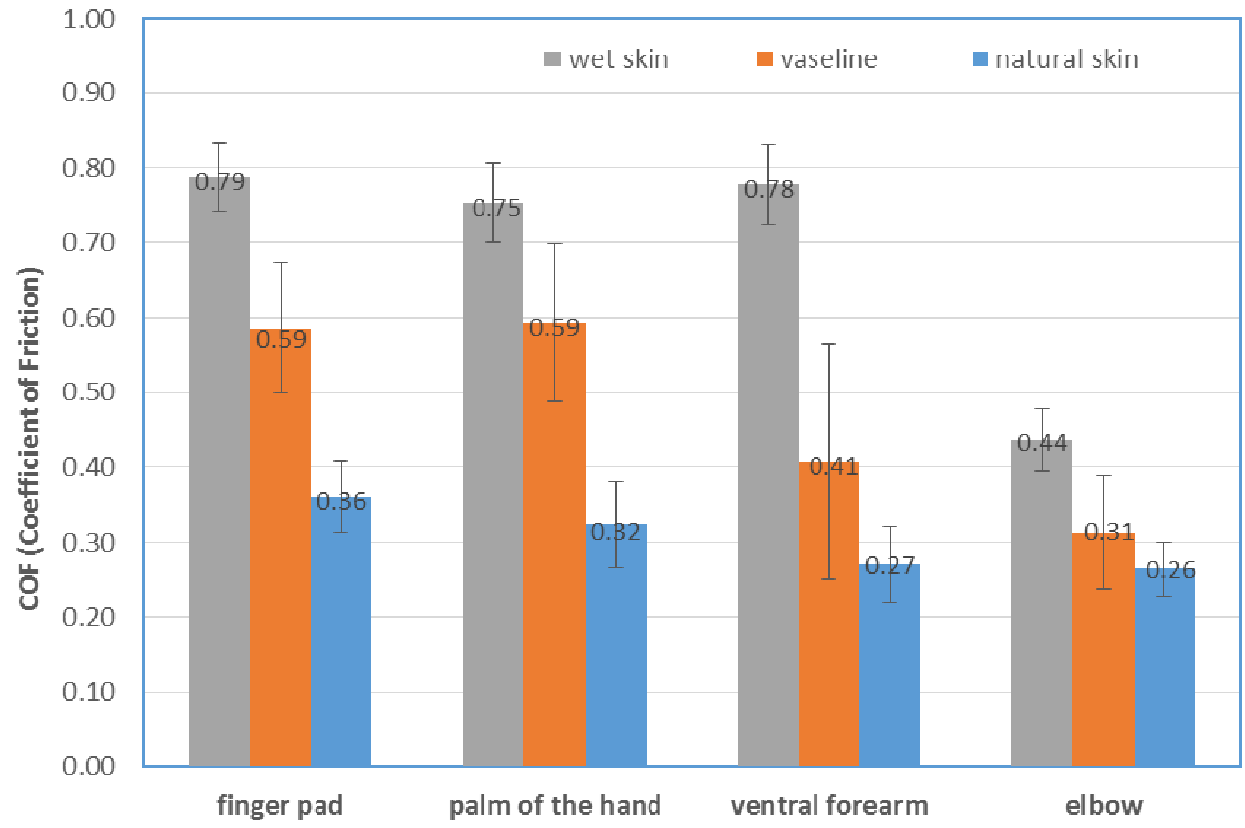

Figure 8. Coefficient of friction (COF) for a reference hospital fabric rubbing against different body regions under different lubricating conditions.

The relationship between different substances applied to the skin (lubricating conditions) and fabric friction has not been studied in detail before. Only the moisture content between the human skin and textiles has been the object of several studies [7,23]. Figure 8 shows the effect of different lubricating conditions: Vaseline (Vaseline was scattered and absorbed by the skin prior to testing) and wet skin, on the coefficient of friction for four different body regions. It can be seen from Figure 8 that the effect of Vaseline is different according to the anatomical body region investigated. However, the coefficient of friction always increases with the addition of Vaseline if compared to the natural skin conditions. 


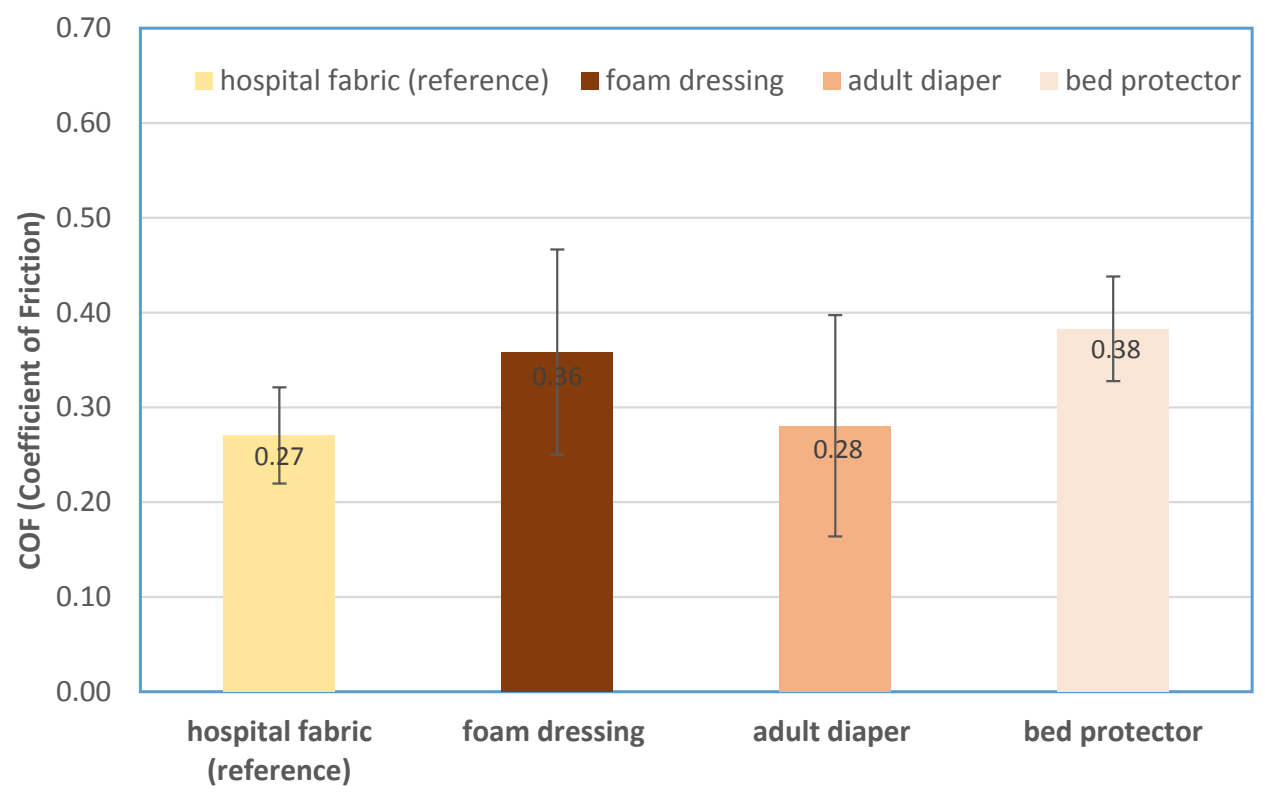

Figure 9. Coefficient of friction (COF) for four different hospital fabrics rubbing against the ventral forearm under unlubricated conditions (natural skin).

The surface of the skin is protected by a lipid film that is composed of water (from sweat) and sebum (from sebaceous glands) that covers the stratum corneum and influences the skin adhesion properties. The spread of Vaseline through the skin can act as a barrier to lock moisture in the skin and, consequently, increasing in the coefficient of friction. In fact, it was shown by Nacht et al. [24] in the early 1980s, that a combination effect can take place with the use of occlusive agents, such as Vaseline. Initially, the coefficient of friction decreases due to the lubricant properties of the Vaseline, while later on, the coefficient increases over the baseline as a consequence of the increased moisturization induced by the occlusion. Viscous lubricants, such as Vaseline and glycerin, may hydrate the skin surface by reducing the rate of transepidermal water loss (TEWL); this brings about a subsequent increase in the friction coefficient induced by the slow and prolonged hydrating effect [24].

The same trend can be seen for wet skin rubbing against a reference hospital fabric. However, the friction of the skin increased from natural skin (dry) to wet skin by a factor of approximately two (e.g., for the elbow body region, the COF increased from $\mu=0.26$ up to $\mu=0.44$ ). Our measurements confirm the previous results of $[25,26]$, who also observed factors between 1.5 and 7 for skin friction before and after immersion in water. According to [7], this large spread probably derives from the diversity of test methods, materials and experimental parameters used, the time delay between the friction measurement and the water exposure of the skin being the most important factor.

The large increase in the coefficients of friction in the presence of water is due to the mechanical properties of the stratum corneum that are moisture dependent [27]. Water reduces the elastic modulus of the stratum corneum (plasticizing effect) due to smoothening of skin roughness asperities and consequently increasing in the real contact area, inducing a risen adhesion in the component of friction. However, in contrast with hydrated skin, water films (full films) on the skin surface can cause hydrodynamic lubrication, resulting in much lower coefficients of friction.

Concerning the effect of different body regions, Figure 8 shows that the coefficient of friction varies significantly along the human body. Friction is considerably lower in the elbow region than in other body parts (e.g., finger pad). The observed variations were mainly attributed to differences in skin hydration with a tendency to greater friction at regions, such as the finger pad and the palm of the hand due to higher skin hydration. The influence of anatomical region on friction has already been investigated in previous studies [28,29], confirming our conclusions. 
Figure 9 shows the coefficient of friction for different hospital fabrics rubbing against the ventral forearm for natural dry skin. The coefficient of friction obtained for the four different hospital fabrics, tested against the ventral forearm under natural skin conditions, varies between 0.27 (hospital fabric) and 0.38 (bed protector).

Several studies have demonstrated that the skin friction of fabrics is influenced by parameters such as the fiber materials, structure and finishing. The results shown in Figure 2 indicated considerable differences in friction between natural (wool, $\mu \sim 0.75$ ) and synthetic (polyamide, $\mu \sim 0.55$ ) fabrics, with natural fabrics showing greater friction, probably due to their hairiness/fine loops.

In our experiments, no significant correlation was found for the selected fabrics under these contact conditions. However, it is possible to observe that the hospital fabric displays the lowest coefficient of friction. This fact is in agreement with some authors who state that the fabrics that display the lowest friction coefficient are those with a greater hydrophilic tendency.

According to the Braden Scale for Predicting Pressure Ulcer Risk, prolonged pressures on body parts, as well friction and shear between the human skin and textiles, can lead to superficial abrasions and tissue deformation. When the layers of skin are deformed/compressed between a bone and a hard surface, blood is squeezed out of the underlying tissue, and the blood circulation is obstructed, causing a lack of oxygen, leading to tissue death. The skin will then start to break down, and a pressure ulcer will develop.

As demonstrated by our experiments, moisture (e.g., due to incontinence or perspiration) can, in fact, accelerate and promote pressure ulcers' formation, since the coefficient of friction between the skin and fabrics increased from dry to wet skin by a factor of more than two in majority of the cases.

\section{Conclusions}

- Results demonstrated that the coefficient of friction (COF) of a reference hospital fabric against skin is influenced by the human body region and lubricating/physiological skin conditions (skin moisture content).

- For the different body regions, the average COF of wet skin exceeded those in the natural skin condition by a factor of more than two, with the friction increasing with the moisture content. In this way, moisture (e.g., due to incontinence) can accelerate/promote skin decubitus formation.

- For the different body regions, the coefficient of friction always increases with the addition of Vaseline if compared to the natural skin conditions. The spreading of Vaseline on the skin can act as a barrier to lock moisture in the skin.

- Natural skin conditions (dry skin) produce the lowest COF for the different body regions.

- Concerning the effect of different body regions, the coefficient of friction varies significantly along the human body. The observed variations were mainly attributed to differences in skin hydration, with a tendency to greater friction at regions such as the finger pad and the palm of the hand, due to higher skin hydration.

- In this investigation, no significant correlation was found for the COF of the four different hospital fabrics.

Acknowledgments: The author Luís M. Vilhena gratefully acknowledges the financial support of the Portuguese Foundation for Science and Technology (FCT), through the program QREN-POPH, reference: SFRH/BPD/92787/2013.

Author Contributions: All authors contributed equally.

Conflicts of Interest: The authors declare no conflict of interest. 


\section{References}

1. Jost, H.P. Lubrication (Tribology) Education and Research. In A Report on the Present Position and the Industry's Needs; Department of Education and Science, Her Majesty's Stationery Office (HMSO): London, UK, 1966.

2. Johnson, S.A.; Gorman, D.M.; Adams, M.J.; Briscoe, B.J. The friction and lubrication of human stratum corneum. In Tribology Series-Thin Films in Tribology. In Proceedings of the 19th Leeds-Lyon Symposium on Tribology held at the Institute of Tribology, University of Leeds, Amsterdam, The Netherlands, 8-11 September 1993; Dowson, D., et al, Eds.; Volume 25, pp. 663-672.

3. Dowson, D. Tribology and the skin surface. In Bioengineering of the skin: Skin surface imaging and analysis; Wilhelm, K.-P., Elsner, P., Berardesca, E., Maibach, H.I., Eds.; CRC Press: Boca Raton, FL, USA, 1997; pp. 159-180.

4. Adams, M.; Briscoe, B.; Johnson, S. Friction and lubrication of human skin. Tribol. Lett. 2007, 26, $239-253$. [CrossRef]

5. Koudine, A.A.; Barquins, M.; Anthoine, P.H.; Aubert, L.; Leveque, J.L. Frictional properties of skin: proposal of a new approach. Int. J. Cosmet. Sci. 2000, 22, 11-20. [CrossRef] [PubMed]

6. Pailler-Mattei, C.; Zahouani, H. Study of adhesion forces and mechanical properties of human skin in vivo. J. Adhes. Sci. Technol. 2004, 18, 1739-1758. [CrossRef]

7. Gerhardt, L.-C.; Strassle, V.; Lenz, A.; Spencer, N.D.; Derler, S. Influence of epidermal hydration on the friction of human skin against textiles. J. R. Soc. Interface 2008, 5, 1317-1328. [CrossRef] [PubMed]

8. Hendriks, C.; Franklin, S. Influence of surface roughness, material and climate conditions on the friction of human skin. Tribol. Lett. 2010, 37, 361-373. [CrossRef]

9. Nacht, S.; Close, J.-A.; Yeung, D.; Gans, E.H. Skin friction coefficient: Changes induced by skin hydration and emollient application and correlation with perceived skin feel. J. Soc. Cosmet. Chem. 1981, 32, 55-65.

10. Adams, M.; Briscoe, B.; Johnson, S. Friction and lubrication of human skin. Tribol. Lett. 2007, 26, $239-253$. [CrossRef]

11. Johnson, S.A.; Gorman, D.M.; Adams, M.J.; Briscoe, B.J. The friction and lubrication of human stratum corneum. In Tribology Series Thin Films in Tribology, Proceedings of the 19th Leeds-Lyon Symposium on Tribology held at the Institute of Tribology, University of Leeds; Dowson, D., Ed.; Elsevier: Amsterdam, The Netherlands; Volume 25, pp. 663-672.

12. Denda, M. Dry Skin and Moisturizers: Chemistry and Function; LodeA, M., Maibach, N.H., Eds.; CRC Press: Boca Raton, FL, USA, 2000; pp. 147-153.

13. Wolfram, L.J. Friction of skin. J. Soc. Cosmet. Chem. 1983, 34, 465-476.

14. Hills, R.J.; Unsworth, A.; Ive, F.A. A comparative study of the frictional properties of emollient bath additives using porcine skin. Br. J. Dermatol. 1994, 130, 37-41. [CrossRef] [PubMed]

15. Johnson, S.A.; Gorman, D.M.; Adams, M.J.; Briscoe, B.J. The Friction and Lubrication of Human Stratum Corneum. In Proceedings of the 19th Leeds-Lyon Symposium on Tribology, Thin Films in Tribology, Leeds, UK, 8-11 September 1992; Elsevier Science Publishers: Amsterdam, The Netherlands, 1993; pp. 663-672.

16. Derler, S.; Gerhardt, L.-C. Tribology of Skin: Review and Analysis of Experimental Results for the Friction Coefficient of Human Skin. Tribol. Lett. 2012, 45, 1-27. [CrossRef]

17. Van Der Heide, E.; Zeng, X.; Masen, M.A. Skin tribology: Science friction? 2013, 1, 130-142. [CrossRef]

18. Xu, F.; Li, T.J.; Seffen, K.A. Skin thermal pain modeling-A holistic method. J. Therm. Biol. 2008, 33, $223-237$. [CrossRef]

19. Essick, G.K.; McGlone, F.; Dancer, C.; Fabricant, D.; Ragin, Y.; Phillips, N. Therese Jones, Steve Guest, Quantitative assessment of pleasant touch. Neurosci. Biobehav. Rev. 2010, 34, 192-203. [CrossRef] [PubMed]

20. Barnes, C.J.; Childs, T.H.C.; Henson, B.; Southee, C.H. Surface finish and touch-a case study in a new human factors tribology. Wear 2004, 257, 740-750. [CrossRef]

21. Ramalho, A.; Silva, C.L.; Pais, A.A.C.C.; Sousa, J.J.S. In vivo friction study of human palmoplantar skin against glass. Tribol. Fin. J. Tribol. 2006, 25, 14-23.

22. Ramalho, A.; Szekeres, N.P.; Fernandes, E. Friction and tactile perception of textile fabrics. Tribol. Int. 2013, 63, 29-33. [CrossRef]

23. Ramalho, A.; Silva, C.L.; Pais, A.A.C.C.; Sousa, J.J.S. In vivo friction study of human skin: Influence of moisturizers on different anatomical sites. Wear 2007, 263, 1044-1049. [CrossRef] 
24. Nacht, S.; Close, J.-A.; Yeung, D.; Gans, E.H. Skin friction coefficient: changes induced by skin hydration and emollient application and correlation with perceived skin feel. J. Soc. Cosmet. Chem. 1981, 32, 55-65.

25. Kenins, P. Influence of fiberb type and moisture on measured fabric-to-skin friction. Text. Res. J. 1994, 64, 722-728. [CrossRef]

26. Derler, S.; Schrade, U.; Gerhardt, L.-C. Tribology of human skin and mechanical skin equivalents in contact with textiles. Wear 2007, 263, 1112-1116. [CrossRef]

27. Johnson, S.A.; Gorman, D.M.; Adams, M.J.; Briscoe, B.J. The friction and lubrication of human stratum corneum. In Thin Films in Tribology; Dowson, D., Ed.; Elsevier Science Publishers: Amsterdam, The Netherlands, 1993; pp. 663-672.

28. Cua, A.B.; Wilhelm, K.P.; Maibach, H.I. Frictional properties of human skin: Relation to age, sex and anatomical region, stratum corneum hydration and transepidermal water loss. Br. J. Dermatol. 1990, 123, 473-479. [CrossRef] [PubMed]

29. Zhu, Y.H.; Song, S.P.; Luo, W.; Elias, P.M.; Man, M.Q. Characterization of skin friction coefficient, and relationship to stratum corneum hydration in a normal Chinese population. Skin Pharmacol. Physiol. 2011, 24, 81-86. [CrossRef] [PubMed]

(C) 2016 by the authors; licensee MDPI, Basel, Switzerland. This article is an open access article distributed under the terms and conditions of the Creative Commons by Attribution (CC-BY) license (http:/ / creativecommons.org/licenses/by/4.0/). 